\title{
Comparison of Retention between Two Dental Root Canal Core Build Up Materials and Silanized and Non-Silanized Glass Fibre Posts: An Invitro Study
}

\author{
Dr. Sunitha Shamnur ${ }^{1}$, Dr. Nandeeshwar DB ${ }^{2}$, Dr. Sakshi Verma ${ }^{3}$, Dr. Puja C Yavagal $^{4}$ \\ ${ }^{1}$ Professor, Department of Prosthodontics and Crown and Bridge, Bapuji Dental College and Hospital,Davangere, Karnataka, \\ India, 577-004. \\ ${ }^{2}$ Professor and Head, Department of Prosthodontics and Crown and Bridge, Bapuji Dental College and Hospital, Davangere, \\ Karnataka, India, 577-004. \\ ${ }^{3}$ Postgraduate, Department of Prosthodontics and Crown and Bridge, Bapuji Dental College and Hospital, Davangere, Karnataka, \\ India, 577-004. \\ ${ }^{4}$ Professor, Department of Public Health Dentistry, Bapuji Dental College and Hospital, Davangere, Karnataka, India, $577-004$.
}

\begin{abstract}
Background: Various resin-based core builds up materials are commercially available in market but their clinical use should follow recommendations of bond strength measurement studies.

Objective: to evaluate the retention between two commercially available core build up materials and silanized and non-silanized glass fibre posts.

Methodology: The retention between two commercially available core build up materials (Core X Flow and Light Core) and Silanized and Non- Silanized glass fiber posts with ten samples in each group were assessed using 'pull out test' in universal testing machine. Student's unpaired ' $t$ ' test was used for inter group comparison by fixing significance level at $p \leq 0.05$.

Results: The retention force was higher in silanized fibre post group compared to non-silanized posts ( $p=0.02)$. Among the silanized posts, the retention force was significantly higher in CORE X FLOW group compared to LIGHT CORE group (p=0.03). Conclusion: The retention of posts improved with silanization. With silanization, the retention force was significantly higher with 'CORE X FLOW' compared to 'LIGHT CORE' core build up material.
\end{abstract}

KEYWORDS: Core Build Up, Dental, Fibre Posts, Root Canal, Silanized.

\section{INTRODUCTION}

Restoration of teeth which are weakened due to caries, previous restoration, fracture, endodontic access opening and instrumentation is challenging. One of the common causes of endodontically treated tooth loss is poor post endodontic restoration.[1] Failure rate of endodontically treated teeth was almost double in cases without adequate post endodontic restoration.[2] However, endodontically treated teeth that receive timely, definitive restorative treatment have significantly greater longevity than non-restored teeth.[3]The post endodontic restoration very often includes the placement of post in the root canal to provide retention of core material and to provide coronal radicular stabilization. Traditionally, posts were either prefabricated or custom cast in metal and luted with zinc phosphate or glass ionomer cements.[4] However fiber posts were rapidly accepted by clinicians and provided a viable alternative to cast metal posts for the restoration of root filled teeth. The major advantage of fiber posts is their similar elastic modulus to dentine, producing a stress field similar to that of natural teeth, whereas metal posts exhibit high stress concentrations at the postdentine interface. Clinical studies have demonstrated high success rates without the occurrence of root fractures. Moreover, fiber posts are ready to use whereas the construction of a cast post and core is more time consuming and demands extra clinic and laboratory time.[4] With a significant loss of coronal tooth structure, abutment build-up around a fiber post is required. Several dental materials have been used for core build-up procedures, some as direct and some as indirect, such as custom cast post and core. The materials used for direct core build-up includes high copper amalgam, visible light cured resin composite, auto cured titanium containing composite, polyacid modified composite, resin-modified glass ionomer, and a silver cermet cement. Different resin composite materials are available in the market to build up root-filled teeth. Although composites that are specifically designed for 


\section{International Journal of Current Science Research and Review}

ISSN: 2581-8341

Volume 05 Issue 02 February 2022

DOI: 10.47191/ijesrr/V5-i2-37, Impact Factor: 5.825

IJCSRR@ 2022

Www.ijcsrr.org

core build-ups are available; hybrid and flowable composites have also been employed for the same purpose.[5] Retention between core and prefabricated post is critical to post and core longevity. The ability of a post and core system to tolerate the masticatory forces and remain firmly seated on the tooth is essential for longevity of a restoration. If either the post itself or the core material fails the restoration will eventually fail.[6] Chemical treatments of the post lead to a greater mechanical retention by roughening the post surface. Some of the chemical solutions used for post surface treatments are potassium permanganate, hydrofluoric acid, silane and hydrogen peroxide.[7] Glass fibre reinforced posts have been treated with silane in order to improve the adhesion between fibre and resin matrix. Silane coupling agents are hybrid organic-inorganic compounds that can mediate adhesion between inorganic and organic matrices through an intrinsic dual reactivity. The silane coupling agent most commonly used for dental applications is a prehydrolyzed monofunctional methacryloxypropyl-trimethoxysilane (MPS) diluted in an ethanol-water solution with a pH between 4 and 5.[8] Glass fibre reinforced posts have been treated with silanein order to improve the adhesion between fibre and resin matrix. But limited information is available regarding potential effect of silane treatment on adhesion of fibre post as whole to resin matrix. [9] Various resin-based core build up materials are commercially available in market but their clinical use should follow recommendations of bond strength measurement studies. Hence, the present study aims to evaluate the retention between two commercially available core build up materials and silanized and non-silanized glass fibre posts.

\section{METHODOLOGY}

The present in vitro study was conducted to evaluate the retention between two commercially available core build up materials (Core X Flow and Light Core) and Silanized and Non- Silanized glass fiber posts. Ten samples in each group were prepared according to the criteria mentioned by Millestein.[10] They were then subjected to pull out test in universal testing machine. Study was conducted in the Department of Prosthodontics, Bapuji Dental College and Hospital, and Department of Textile and Chemistry, Bapuji Institute of Engineering and Technology, Davangere. Materials used in this study were: Dual cure core build up material (CORE X FLOW, Dentsply, India) (Batch no.- 150126) ; Light cure core build up material (LIGHT CORE, Bisco, Inc.) (Batch no.- 1600004193) ;Glass fibre reinforced prefabricated post (REFORPOST by Angelus Dental solutions, Brazil) (Batch no. - 11409111-0122092014) ; and Silane agent ( RELY X 3M ESPE)( Batch no.- N636821)

\section{A. Preparation of the molds}

Teflon molds were customized containing a cylindrical cavity ( $9 \mathrm{~mm}$ in diameter and $6 \mathrm{~mm}$ deep) with lower channel (1.1 x $12 \mathrm{~mm}$ ) for post core fabrication.

\section{B. Preparation of the samples without Silanizing the posts}

The upper head till the first mark $(1 \mathrm{~mm})$ was cut from the post. It was then placed onto the Teflon mold with $3 \mathrm{~mm}$ post exposed in the cylindrical cavity.

\section{Preparation of samples with Light Core build up material}

The material was condensed layer by layer around each post with the parallelogram condenser and light cured. (Image 1)By gentle tapping on the other side of Teflon mold the post core assembly was retrieved and the same procedure was followed to fabricate the rest of the samples and were numbered 1 to 10 .

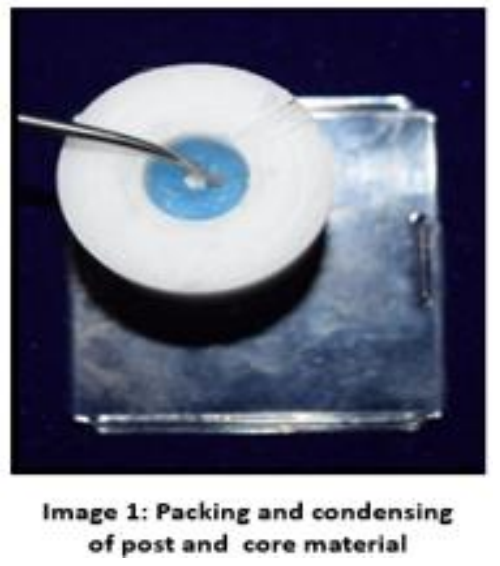




\section{International Journal of Current Science Research and Review}

ISSN: 2581-8341

Volume 05 Issue 02 February 2022

DOI: 10.47191/ijesrr/V5-i2-37, Impact Factor: 5.825

IJCSRR@ 2022

www.ijcsrr.org

\section{Preparation of samples with CORE X FLOW core build up material}

The material was applied layer by layer around each post with the mixing tip and light cured. By gentle tapping on the other side of Teflon mold the post core assembly was retrieved and the same procedure was followed to fabricate the rest of the samples and were numbered 1 to 10 .

\section{E. Preparation of the samples by Silanizing the posts}

First the upper head till the first mark $(1 \mathrm{~mm})$ was cut from the post. They were then treated with silane coupling agent for 60s.followed by air drying. Post was then placed onto the Teflon mold with $3 \mathrm{~mm}$ post expo cavity. (Image 2)

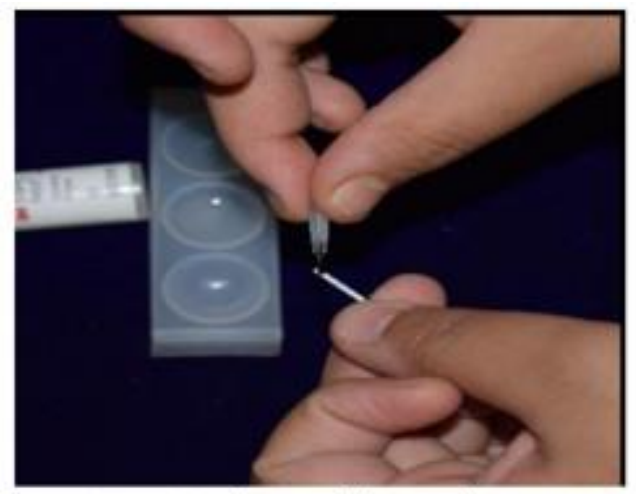

Image 2:Application of silane to the post

For Preparation of samples using 'LIGHT CORE' core build up material, the material was condensed layer by layer around each post with the parallelogram condenser and light cured. By gentle tapping on the other side of Teflon mold the post core assembly was retrieved and the same procedure was followed to fabricate the rest of the samples and were numbered 1 to 10 .For preparation of samples using CORE X FLOW core build up material, the material was applied layer by layer around each post with the mixing tip and light cured. By gentle tapping on the other side of Teflon mold the post core assembly was retrieved and the same procedure was followed to fabricate the rest of the samples and were numbered 1 to 10 .

\section{F. Finishing and polishing of samples}

Finishing of samples were carried out using sof-lex discs followed by subgrouping of samples.

\section{G. Measurement of retention of post to core build up material by using the pull-out test}

Post- core retention was determined by recording the force required to dislodge the post from the core material. Individual post core assemblies were mounted in universal testing machine using a customized jig.(Image 3) The universal testing machine (UTM) was used to test the tension, compression, bend, flexure, peel, shear, stress relaxation, and creep and provided a range of cross head speeds which could be set from $0.5 \mathrm{~mm} / \mathrm{min}$ to $15 \mathrm{~mm} / \mathrm{min}$. The samples prepared in this study were placed in the machine between the grips. As the machine was started it began to apply an increasing load on specimen at cross head speed of $1 \mathrm{~mm} / \mathrm{min}$. Throughout the tests the control system and its associated software recorded the load and extension of the sample.

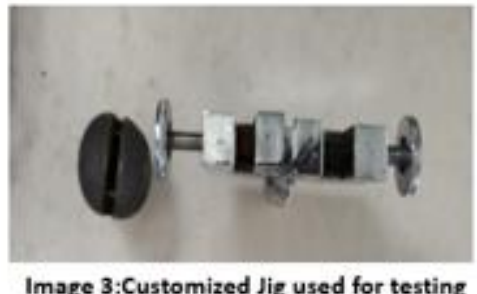

\section{H. Statistical Analysis}

The data was subjected to statistical analysis using Statistical Package for Social Sciences version 20 (SPSS Pvt Ltd, Chicago, IL, USA). The data showed normal distribution when Shapiro-Wilk's test was applied hence parametric tests were used. Student's unpaired ' $\mathrm{t}$ ' test was used for inter group comparison by fixing significance level at $\mathrm{p} \leq 0.05$. 


\section{International Journal of Current Science Research and Review}

ISSN: 2581-8341

Volume 05 Issue 02 February 2022

DOI: 10.47191/ijesrr/V5-i2-37, Impact Factor: 5.825

IJCSRR@ 2022

www.ijcsrr.org

\section{RESULTS}

The retention force was higher in silanized fiber post group compared to non-silanized posts. This difference was statistically significant in CORE X FLOW core build up group $(\mathrm{p}=0.02)$.(Table 1)Among the silanized posts , the retention force was significantly higher in CORE X FLOW group compared to LIGHT CORE group ( $\mathrm{p}=0.03$ ).In non-silanized posts ,there was no significant difference in retention forces between CORE X FLOW group and LIGHT CORE group.(Table 2)

Table 1: Comparison of retention force (Kgf) between silanized and non-silanized glass fiber posts

\begin{tabular}{|c|c|c|c|c|c|c|}
\hline Material & Group & $\mathrm{N}$ & Mean \pm SD & $\begin{array}{l}\text { Mean Difference } \\
(95 \% \mathrm{CI})\end{array}$ & Test Value & p- value \\
\hline \multirow[t]{2}{*}{ A } & $S$ & 10 & $8.11 \pm 1.68$ & \multirow[t]{2}{*}{$\begin{array}{l}1.53 \\
(0.32,2.74)\end{array}$} & \multirow[t]{2}{*}{2.65} & \multirow[t]{2}{*}{$0.02 *$} \\
\hline & NS & 10 & $6.58 \pm 0.71$ & & & \\
\hline \multirow[b]{2}{*}{ B } & S & 10 & $6.54 \pm 1.28$ & \multirow{2}{*}{$\begin{array}{l}0.77 \\
(-0.40,1.94)\end{array}$} & \multirow[t]{2}{*}{1.38} & \multirow[t]{2}{*}{0.18} \\
\hline & NS & 10 & $5.77 \pm 1.21$ & & & \\
\hline
\end{tabular}

Table 2: Comparison of retention force (Kgf) between different core build up material groups

\begin{tabular}{|c|c|c|c|c|c|c|}
\hline Group & Material & $\mathrm{N}$ & Mean \pm SD & Mean Difference $(95 \% \mathrm{CI})$ & Test Value & p- value \\
\hline \multirow[b]{2}{*}{ S } & $\mathrm{A}$ & 10 & $8.11 \pm 1.68$ & \multirow[t]{2}{*}{$1.57(0.16-2.97)$} & \multirow[b]{2}{*}{2.34} & \multirow[b]{2}{*}{$0.03^{*}$} \\
\hline & B & 10 & $6.54 \pm 1.28$ & & & \\
\hline \multirow[b]{2}{*}{ NS } & $\mathrm{A}$ & 10 & $6.58 \pm 0.71$ & \multirow[t]{2}{*}{$0.80(-0.12-1.73)$} & \multirow[b]{2}{*}{1.82} & \multirow[t]{2}{*}{$0.09(\mathrm{NS})$} \\
\hline & B & 10 & $5.77 \pm 1.21$ & & & \\
\hline
\end{tabular}

\section{DISCUSSION}

The present study evaluated and compared the retentive property of two commercially available core build up materials and silanized and non-silanized glass fiber posts. The results indicated that silanization improved retentive property of CORE X FLOW posts compared to non silanized posts. The CORE X FLOW core build up posts exhibited better retentive property compared to 'LIGHT CORE' core build up posts. Similar results were seen in few studies where silanized posts performed better than non-silanized. [11,12] A systematic review by Moraes et al, indicated that silanization improved the retention of fiber posts luted into root canals [12] However, silanization alone as a surface treatment does not improve the bond strength. Combination of chemical pre surface treatments followed by silanization significantly enhances the bond strength at the post/adhesive interface.[13] In a previous study by Spinhayer et al, dual-cure core build up material like CORE X Flow had a significant and favorable impact on flexure strength of posts ( $E_{\text {flex }}(p=0.0007)$ [14]. CORE X FLOW is a micro hybrid, nano filled, dual cure, flowable core build up resin with flexural strength of $120 \mathrm{MPa}$ (According to manufacturer's data).[14].In a study by Kim et al , the mean fracture strength was highest in the group with quartz fibre post (D.T. Light-post) cemented with resin cement and a core foundation formed with composite resin (LIGHT-CORE).[15] A study by Kocak et al, revealed that light-core composite showed more bond strength than the micro hybrid composite. [16] A variety of experimental tests has been described for evaluating the strength of the bond between core and the fibre posts, such as the pull-out test, the micro tensile test, and the push-out test. For assessment of retention of posts, push-out and pull-out tests have been conventionally used .Until now, attempts to include micro tensile techniques to compensate for the limitations of 


\section{International Journal of Current Science Research and Review}

ISSN: 2581-8341

Volume 05 Issue 02 February 2022

DOI: 10.47191/ijesrr/V5-i2-37, Impact Factor: 5.825

IJCSRR@ 2022

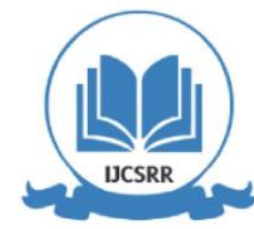

www.ijcsrr.org

conventional shear and tensile bond strength tests have failed, mostly due to problems like untimely failures .With the present experimental set-up, the pull-out test design was chosen for evaluating the retention of fibre-glass posts to core build up material using the universal testing machine and a specialized jig at a cross head speed of $1 \mathrm{~mm} / \mathrm{min}$ similar to a study done by Webber et al,.[17]The retention property of post was assessed by recording the force required to separate the post from the core. The post which required more force to be dislodged was considered to have superior retentive property. In our study maximum retention force was recorded for CORE X FLOW core build up material with silanized post. This could be attributed to the flowable consistency of the material which exhibits lower viscosity and improved adaptability at the surface of the post. The lower filler/resin ratios offer high flow, better adaptation, easier insertion and great elasticity. Also, flowable and light-activated materials, tend to have an easier handling and a better integration with the fibre post surface, thus leaving little room for bubbles/voids within the abutment, and for discontinuities along the core- post interface. [18]. The surface of the fibre post is composed of different components; the resin matrix, inorganic filler particles, and fibers. Because of the differences in chemical structure, no bonding is expected to occur between the methacrylate-based resin of the core and the resin of the fibre post matrix. On this account, chemical adhesion after silane treatment of the post surfaces may only be established between the resin of the core material and the exposed glass fibers of the posts or filler particles. Perhaps this could be one of the reasons of CORE X FLOW performing better retentive property than LIGHT CORE (BISCO, INC) post silanization. Since the contribution of the chemical bond in coupling post and core materials through silanes can be expected to be low, the mechanism most likely involved in the enhancement of the post-core bond seen in the present study can be identified in the improvement in post surface wettability following silane coating. the silane, assists substrate wetting, Also the van der Waals' forces would become effective, providing a physical adhesion, which contributes to the chemical reactions. Silanes are believed to increase the resistance of the bonds to chemical dissolution, particularly from water. In addition, due to their elastic properties, silanes would be able to absorb the stress that may develop at the interface as a result of differences in thermal expansion coefficients of the interfacing materials. [9] Small sample size and in vitro design restrict the generalizability of the present study.

\section{CONCLUSION}

The retention of posts improved with silanization. Among the silanized posts, the retention force was significantly higher with 'CORE X FLOW' compared to 'LIGHT CORE' core build up material.

\section{CONFLICT OF INTEREST: Nil}

\section{REFERENCES}

1. Trabert KC, Cooney JP. The endodonticlly treated tooth - Restorative concepts and techniques. Dent Clin North Am. 1984; 28: $923-42$.

2. Swartz DB, Skidmore AE, Griffin JA Jr. Twenty years of endodontic success and failure. J Endod. 1983 May;9(5):198202.

3. Hunter M, Flood A. The restoration of endodontically treated teeth. Part 1: Treatment Planning and Restorative Principles. Aus Dent J .1998; 33: 481-90

4. Coloman HL. Restoration of endodontically treated teeth. Dent Clin North Am .1979; 23:647- 661

5. Sadek FT, Monticelli F, Goracci C, Tay FR, Cardoso PE, Ferrari M. Bond strength performance of different resin composites used as core materials around fiber posts. Dent Mater. 2007 Jan;23(1):95-9.

6. Cohen BI, Pagnillo MK, Newman I, Muikant BL, Deutsch AS. Cyclic fatigue testing of five endodontic post designs supported by four core materials. J Prosthet Dent. 1997;78:458-64

7. Zahra K, Reza T. Effect of ascorbic acid, ethanol and acetone on adhesion between the treated fiber posts and composite resin cores. J Adv Prosthodont .2012;4:187-91.

8. Perdigão J, Gomes G, Lee IK. The effect of silane on the bond strengths of fiber posts. Dent Mater. 2006 Aug;22(8):7528.

9. Goracci C, Rafaelli O, Monticelli F, Balleri B, Bertelli E, Ferrari M. The adhesion between prefabricated FRC posts and composite resin cores: Microtensile bond strength with and without post-silanization .Dent Mater .2005; 21(5):437-44. 


\section{International Journal of Current Science Research and Review}

ISSN: 2581-8341

Volume 05 Issue 02 February 2022

DOI: 10.47191/ijesrr/V5-i2-37, Impact Factor: 5.825

IJCSRR@ 2022

www.ijesrr.org

10. Millstein PL, Ho J, Nathanson D. Retention between a serrated steel dowel and different core materials. J Prosthet Dent. 1991 Apr;65(4):480-2

11. Kim HD, Lee JH, Ahn KM, Kim HS, Cha HS. Effect of silane activation on shear bond strength of fiber-reinforced composite post to resin cement. J Adv Prosthodont. 2013. May;5(2):104-9.

12. Moraes AP, Sarkis-Onofre R, Moraes RR, Cenci MS, Soares CJ, Pereira-Cenci T. Can Silanization Increase the Retention of Glass-fiber posts? A Systematic Review and Meta-analysis of In Vitro Studies. Oper Dent. 2015 Nov-Dec;40(6):56780.

13. Belwalkar VR, Gade J, Mankar NP. Comparison of the effect of shear bond strength with silane and other three chemical presurface treatments of a glass fiber-reinforced post on adhesion with a resin-based luting agent: An in vitro study. Contemp Clin Dent. 2016 .Apr-Jun;7(2):193-7.

14. Spinhayer L, Bui ATB, Leprince JG, Hardy CMF. Core build-up resin composites: an in-vitro comparative study. Biomater Investig Dent. 2020 Nov 3;7(1):159-166.

15. Kim YH, Lee JH. Influence of modification in core building procedure on fracture strength and failure patterns of premolars restored with fiber post and composite core. J Adv Prosthodont. 2012 Feb;4(1):37-42.

16. Koçak MM, Cengiz S, Koçak S. Bond Strength of Resin Composites used as Core Materials around Different Types of Fiber Posts. Int J Experiment Dent Sci .2012; 1(2):81-83.

17. Webber MB, Michida SM, Marson FC, de Oliveira GC, Silva Cde O. Analysis of bond strength by pull out test on fibre glass posts cemented in different lengths. J Int Oral Health. 2015 Apr;7(4):7-12.

18. Sadek FT, Monticelli F, Goracci C, Tay FR, Cardoso PE, Ferrari M. Bond strength performance of different resin composites used as core materials around fiber posts. Dent Mater. 2007 Jan;23(1):95-9

Cite this Article: Dr. Sunitha Shamnur, Dr. Nandeeshwar DB, Dr. Sakshi Verma, Dr. Puja C Yavagal (2022). Comparison of Retention between Two Dental Root Canal Core Build Up Materials and Silanized and Non-Silanized Glass Fibre Posts: An Invitro Study. International Journal of Current Science Research and Review, 5(2), 601-606 